\title{
Awareness and Misconception about HIV/AIDS Transmission among Selected Bangladesh Army Troops
}

\author{
Mahmud SN ${ }^{1}$, Irfan SMN ${ }^{2}$
}

DOI: https://doi.org/10.3329/jafmc.v14i2.45904

\begin{abstract}
Introduction: AIDS is a fatal illness that breaks down the body's immune system, leaving the victim vulnerable to lifethreatening opportunistic infections, neurological disorders or unusual malignancies, having no effective treatment till now.
\end{abstract}

Objectives: To assess the awareness and misconception about the transmission of HIVIAIDS among the troops of Bangladesh Army.

Materials and Methods: This cross-sectional study was conducted from September 2011 to December 2011 among purposively selected 125 troops of various Army units of Dhaka Cantonment, Bangladesh. Data were collected by face-to-face interview by pretested structured questionnaire and analyzed by software SPSS version 17.0.

Results: Among the 125 respondents, most (92\%) of them were aware of the transmission of HIVIAIDS and having no significant misconception of its transmission. No association has been found between knowledge of HIV transmission and type of occupation.

Conclusion: Most of the troops of the Bangladesh Army were aware of the transmission of HIVIAIDS and misconception among them was very less. The authority should continue thus status for the betterment of the country.

Key-words: HIV, AIDS, Awareness, Misconception, Bangladesh Army.

\section{Introduction}

Acquired Immune Deficiency Syndrome (AIDS) is a fatal illness caused by a retrovirus known as the Human Immune deficiency Virus (HIV) that breaks down body's immune system, leaving the victim vulnerable to a host of life-threatening opportunistic infection, neurological disorders or unusual malignancies. The term AIDS refers only to the last stage of HIV infection. AIDS can be called modern pandemic, affecting both industrialized and developing countries ${ }^{1}$. Bangladesh is facing growing number of HIV prevalence among high-risk groups such as sex workers, injecting drug users (IDU), men who have sex with men (MSM), and migrants. Dire poverty, political instability, gender inequality, denial and social stigma in Bangladesh, combined with low levels of education make HIV prevention a challenging task ${ }^{2}$. Like many other Asian countries, a good number of patients in Bangladesh have the history of unprotected sex by the commercial sex worker as well as homosexual activities, which is a major risk factor for transmission of HIV infection.

It has been noted that nearly one in five ever-married women who had heard of AIDS did not know if there was any way to prevent it and this was lower $(6 \%)$ among men. Due to wide range of illiteracy and ignorance, the knowledge on HIV/ AIDS among the people is limited. Every year approximately 250,000 people leave abroad for employment ${ }^{2}$. Migrant workers account for a significant number of HIV cases in Bangladesh, primarily because they are subjected to mandatory HIV testing. According to the ICDDR,B 47 of the 259 cases of people living with HIV between 2002-2004 had history of migration. Of these, 29 were males returning from abroad, seven were wives of migrant workers, and four were children of HIV positive migrant workers ${ }^{3}$.

Members of Bangladesh Army are frequently visiting and staying abroad on the event of 'UN Peace Keeping Mission' for a sustained tenure that is compulsory in nature. Usually, these UN missions are located in Africa continent, countries of which are highly exposed to HIVIAIDS and at the same time Bangladesh is one of the largest providers of troops to UN peacekeeping missions. Staying away from family for a prolong period, stressed life-threatening situation, lack of leave facility and amusement, exposed to unrestricted and easily accessible ethnicity for sex can direct Army personnel to get pleasure by unsafe sex, thereby obtain HIV infection. At the same time, soldiers of Bangladesh Army have a different prototype of duty differs from other government services, like restrained to cantonment area, harsh training schedule, droning duty pattern, less extent of social interaction and freedom. All these factors create potent aspiration to have substantial gratification of having sex with professional sex workers or with men whenever they loosen up ${ }^{5}$.

In Bangladesh, the HIV prevalence among the general public is not fully known; currently, available surveillance data only

1. Col Syed Naufel Mahmud, MBBS, MPH, ADGMS (Health), Directorate General of Medical Services, Bangladesh Armed Forces (E-mail: naufelmahmud@yahoo.com) 2.Lt Col SM Nurul Irfan, MBBS, MPH, Trainee Officer, Armed Forces Medical Institute, Dhaka. 
covers high-risk groups. This ambiguity is partly because voluntary and confidential counselling and testing (VCT) services are not widely available in Bangladesh ${ }^{6}$. In such circumstances, awareness on prevention of HIV/AIDS has no substitution which is required to be assessed. The study was conducted to assess the awareness and misconception of armed forces personnel on transmission of HIVIAIDS.

\section{Materials and Methods}

This cross-sectional study was conducted from September 2011 to December 2011 among 125 serving soldiers of Bangladesh Army posted at different units of Dhaka Cantonment. The respondents were selected purposively. Data were collected through face-to-face interview using a pretested questionnaire. Prior to conduct the study ethical clearance was taken from Ethical Committee of Armed Forces Medical Institute (AFMI) and informed written consent was taken from the subjects. Respondent's awareness and misconception regarding transmission of HIVIAIDS were assessed through a structured questionnaire. Awareness on transmission regarding HIVIAIDS has been inquired under the heading of transmission through surgical procedure, breast milk and vertical transmission. Misconception regarding transmission of HIV was assessed in the heading of sharing utensils and through mosquito bites. Data processing and analyses were done using Statistical Package for Social Sciences (SPSS) version 17. Frequencies, percentage, mean and standard deviation (SD) were used for descriptive statistics. Chi-square test was used to evaluate association between variables.

\section{Results}

Mean age of the respondents was $28.48 \pm 6.4$ years and more than half $(51.20 \%)$ of the respondents were in the age group of 21-30 years. The majority were Muslim (96.80\%) and married $(66.40 \%)$, having the education qualification up to SSC $(74.40 \%)$ followed by HSC $(16.0 \%)$. Mean family income was $11307 \pm 2879.86$ taka and $53.60 \%$ of the respondents' monthly family income was between 1000115000 taka. About $40.80 \%$ were general duty followed by tradesman $(32.80 \%)$ and about $36.0 \%$ respondents were serving in army for 11-15 years (Table-I). Out of 125 respondents, $92.0 \%$ were aware of vehicle of transmission of HIV to a person through contaminated surgical procedure and $96.8 \%$ were aware of its transmission through breast milk. At the same time $97.6 \%$ were aware of the transmission of HIVIAIDS through vertical route. About $98.4 \%$ had awareness about the transmission through utensils and $84 \%$ through mosquito bites (Table-II). No significant association was revealed between the occupation of the respondents and awareness about HIV transmission through surgical procedure (Table-III). No significant association was revealed between the occupation of the respondents and misconception about HIV transmission through mosquito bite (Table-IV).
Table 1: Socio-demographic characteristics of respondents $(n=125)$

\begin{tabular}{|c|c|c|c|}
\hline \multicolumn{2}{|c|}{ Socio-demographic characteristics } & Frequency & Percentage \\
\hline \multirow{5}{*}{ Age } & Up to 20 & 12 & 9.60 \\
\hline & $21-30$ & 64 & 51.20 \\
\hline & $31-40$ & 43 & 34.40 \\
\hline & $41-50$ & 6 & 4.8 \\
\hline & \multicolumn{3}{|c|}{ Mean (SD)28.48 $( \pm 6.4)$ years } \\
\hline \multirow[b]{2}{*}{ Religion } & Islam & 121 & 96.8 \\
\hline & Hindu & 4 & 3.2 \\
\hline \multirow[b]{2}{*}{ Marital Status } & Unmarried & 42 & 33.60 \\
\hline & Married & 83 & 66.40 \\
\hline \multirow{3}{*}{ Education } & Up to Class X & 12 & 9.60 \\
\hline & SSC and equivalent & 93 & 74.40 \\
\hline & $\mathrm{HSC}$ & 20 & 16.00 \\
\hline \multirow{4}{*}{ Monthly income (Taka) } & $5000-10000$ & 51 & 40.80 \\
\hline & $10001-15000$ & 67 & 53.60 \\
\hline & $\geq 150001$ & 7 & 5.6 \\
\hline & \multicolumn{3}{|c|}{ Mean (SD)11307 ( \pm 2879.86$)$} \\
\hline \multirow{3}{*}{ Occupation } & General Duty & 51 & 40.80 \\
\hline & Tradesman & 41 & 32.80 \\
\hline & Others & 33 & 26.40 \\
\hline
\end{tabular}

Table-II: Distribution of respondents by status of awareness about transmission of HIVIAIDS $(n=125)$

\begin{tabular}{|l|l|c|c|}
\hline \multicolumn{2}{|c|}{ Domain } & Aware (\%) & Not aware (\%) \\
\hline \multirow{3}{*}{ Awareness } & Through Surgical Procedure & $115(92.0)$ & $10(8.0)$ \\
\cline { 2 - 4 } & Through Breast milk & $121(96.8)$ & $4(3.2)$ \\
\cline { 2 - 4 } & Vertical transmission & $122(97.6)$ & $3(2.4)$ \\
\hline \multirow{2}{*}{ Misconception } & Through sharing utensils & $123(98.4)$ & $2(1.6)$ \\
\cline { 2 - 4 } & Through mosquito bite & $105(84)$ & $20(16)$ \\
\hline
\end{tabular}

Table-III: Association between respondents' occupational status and awareness about the transmission of HIV through surgical procedure $(n=125)$

\begin{tabular}{|c|c|c|c|c|}
\hline \multirow{2}{*}{$\begin{array}{c}\text { Occupational } \\
\text { status }\end{array}$} & \multicolumn{3}{|c|}{ Transmission through surgical procedure } & \multirow{2}{*}{ Statistics } \\
\hline & Yes & No & Total & \\
\hline General duty & $46(36.8)$ & $5(4.0)$ & $51(40.8)$ & \multirow{6}{*}{$\begin{array}{l}\chi^{2}=7.81 \\
d f=4 \\
p>0.05\end{array}$} \\
\hline Tradesman & $41(32.8)$ & $0(.0)$ & $41(32.8)$ & \\
\hline Driver & $16(12.8)$ & $2(1.6)$ & $18(14.4)$ & \\
\hline Cook & $3(2.4)$ & $0(.0)$ & $3(2.4)$ & \\
\hline Others & $9(7.2)$ & $3(2.4)$ & $12(9.6)$ & \\
\hline Total & $115(92.0)$ & $10(8.0)$ & $125(100.0)$ & \\
\hline
\end{tabular}

Table-IV: Association between respondents' occupational status and misconception of transmission of HIV by mosquito bite $(n=125)$

\begin{tabular}{|c|c|c|c|c|}
\hline \multirow{2}{*}{ Occupational status } & \multicolumn{3}{|c|}{ Transmission by mosquito bite } & \multirow{2}{*}{ Statistics } \\
\hline & Yes & No & Total & \\
\hline General duty & $9(7.2)$ & $42(33.6)$ & $51(40.8)$ & \multirow{6}{*}{$\begin{array}{l}\chi^{2}=9.45 \\
d f=4 \\
p>0.05\end{array}$} \\
\hline Tradesman & $3(2.4)$ & $38(30.4)$ & $41(32.8)$ & \\
\hline Driver & $3(2.4)$ & $15(12.0)$ & $18(14.4)$ & \\
\hline Cook & $2(1.6)$ & $1(.8)$ & $3(2.4)$ & \\
\hline Others & $3(2.4)$ & $9(7.2)$ & $12(9.6)$ & \\
\hline Total & $20(16.0)$ & $105(84.0)$ & $125(100.0)$ & \\
\hline
\end{tabular}

\section{Discussion}

In this study, $92.0 \%$ respondents were aware of transmission of HIV through contaminated surgical procedure, and $8.0 \%$ were not aware. It does not correspond with the 2005 population- 
based survey report on AIDS awareness in Bangladesh where it was shown that $59 \%$ of ever-married women and $42 \%$ men of age group $15-54$ years were not aware in this aspect $t^{6,7}$. The study revealed that $96.8 \%$ respondents were aware of transmission of HIV through breast milk. In a study by Hancock T et al ${ }^{8}$ in 1999 among high school freshmen and senior students in California, USA, it was found that out of $40 \%$ of newborn children of HIV infected mother $25 \%$ were infected through breast milk. The awareness on transmission of HIV is quite high among respondents because of education, routine motivation and experience of UN mission service. In the present study it was observed that $97.6 \%$ of the respondents were aware and only $2.4 \%$ respondents were not aware regarding transmission of HIV through vertical route. Itis consistent with a study carried out by Islam MT et al ${ }^{9}$ among staffs of ICDDR,B in June 1998, where $82.7 \%$ respondents were aware of transmission of HIV regarding transmission of HIV through vertical route.

The study depicts that, only $1.6 \%$ respondent had misconception about the transmission of HIV by sharing utensil with AIDS patient and $16 \%$ respondents had misconception about transmission of HIV by mosquito bite. The findings are consistent with a study carried out by Oyewale $\mathrm{TO}^{10}$ in Abuja, Nigeriain 2008 where $15.9 \%$ were reported to have misconception that HIV can be contracted through mosquito bite. It was found from the study that, respondents had no misconception about transmission of HIV by touching an AIDS patient, sharing bed or toilet with AIDS patient. This is inconsistent with the findings of Islam MT et $\mathrm{al}^{9}$ among staffs of ICDDR, Bin June 1998, where 52\% respondents had no misconception about transmission of HIV by sharing toilet with AIDS patient.

The association between the awareness or misconception of the respondents regarding the transmission of HIVIAIDS with occupation revealed no statistically significant relationship $(p>0.05)$ (Table-III, IV). The reason for high awareness level maybe because most of the respondents completed their UN mission and from the experience they were aware of the transmission of HIV. Similarly, the misconception regarding transmission of HIVIAIDS through mosquito bites was less due to the fact that almost all the respondents had experience of serving in the Chittagong hill tracts which exposes them about the mosquito-borne diseases and its transmission.

\section{Conclusion}

The overall awareness status of the respondents was better among the troops of the Bangladesh Army. Current data support to take appropriate measures to augment the awareness status regarding prevention of HIVIAIDS among the study population.

\section{References}

1. K Park. Textbook of Preventive and Social Medicine: epidemiology of communicable disease. 19th edition, Jabalpur India, M/S Banarsidas Bhanot publishers, 2008; 5:285.

2. Joint United Nations Programme on HIVIAIDS, UNICEF, World Health Organization. Children and AIDS: Third Stocktaking Report, 2008. UNICEF; 2008.

3. Davies AA, Borland RM, Blake $\mathrm{C}$ et al. The dynamics of health and return migration. PLoS Medicine. 2011 Jun 21; 8(6):e1001046.

4. Sachdeva RK, Wanchu A. Women's issues in HIV infection. Jk Science 2008; 8(3):129-32.

5. SOUTH ASIA | Aids warning for Bangladesh army. BBC News, 2001.

6. Population \& housing census 2011, Preliminary results July 2011, Bangladesh Bureau of Statistics, Statistical Division, Ministry of Planning, Government of the Peoples Republic of Bangladesh.

7. Musa AK, Khan AH. Statistical Pocket Book of Bangladesh 2004: Bangladesh Bureau of Statistics. Planning Division, Ministry of Planning, Government of the Peoples' Republic of Bangladesh 2006:437-8.

8. Hancoock T, Mikhail BI, Santos A et al. A comparison of HIVI AIDS knowledge among high school freshmen and senior students. Journal of Community Health Nursing 1999; 16(3):151-63.

9. Islam MT, Mostafa G, Bhuiya AU et al. Knowledge on and Attitude toward HIVIAIDS among Staff of an International Organization in Bangladesh, ICDDRB 2002:1.

10. Oyewale TO. HIVIAIDS knowledge and attitude among teachers in Abuja, Nigeria 2008:1-123. 